\title{
Coaching behavior as predictor of athlete satisfaction
}

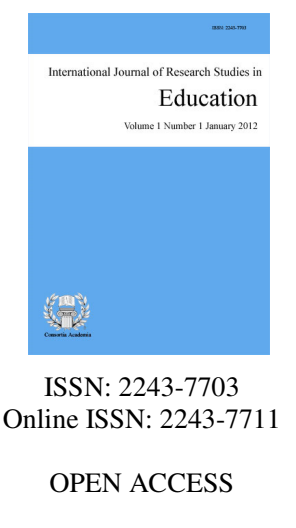

\section{Abstract}

This study determines which domain in the coaching behavior of coaches significantly predicts athlete satisfaction. A quantitative non experimental design using correlational method was used in this study. A total of 179 respondents belonging to the randomly selected high school and college athletes in UM Tagum College. The researcher utilized the two standardized questionnaires to measure the two variables. To measure coaching behavior, the researcher used the Coaching Behavior Scale for Sport and for the athlete satisfaction, Athlete Satisfaction Questionnaire was used. Result indicated that coaching behavior of athletes is high while satisfaction of athletes is much satisfied. There is a significant relationship between coaching behavior and athlete satisfaction. Physical training and conditioning, technical skills, goal setting, competition strategies and personal rapport are domains in coaching behavior of coaches that significantly predicts satisfaction of athletes. On the other hand, mental preparation does not significantly predict athlete satisfaction. The findings of this study provide important inputs to the coaches to strengthen and develop to achieve extremely satisfaction of athletes.

Keywords: education, athlete satisfaction, coaching behavior, high school and college athletes, quantitative non-experimental design, regression analysis, Philippines 


\section{Coaching behavior as predictor of athlete satisfaction}

\section{Introduction}

The most important successful factor of a coach is to help athletes to improve their athletic skill in a wide range of tasks from sequential development and mastery of basic skills, to the more specialized physical, technical, tactical and psychological preparation. Sport organizations are critical places where players are well skilled, and coaches bear a heavy burden of responsibility for their athletes. Coaches in sport organizations are the same as leaders in other organizations, and inevitably face the challenge of maintaining the goals of institutions (Hulin, 2010).

Improving athlete's performance and ensuring continuity of athletes is important for national sport development. However, in national sport archery, there was lot of turnover happened among them and it became a common scenario in Malaysia. Eventually, there is no action has been taken to solve this problem among the sport authorities. In Malaysia, the scenario of having new athletes represents the national team also an issue of sport archery to maintain their performance at the world class league. It is unavoidable that performance may be affect by some factors and previous research had showed that satisfaction has influence the performance (Lorimer, 2011).

The Olympics have come and gone have yet again, the Philippines has failed to rank among the world's best. In over 20 Olympic Games since 1924, the Philippines has won a dismissal 9 medals-2 silvers and 7 bronzes. So what is the matter with Philippine sports? Filipino love sports. The whole country joins Manny Pacquiao when he gets in the ring. Filipino athletes aren't short on passion, and neither lack of talent. So what is it that is making Philippines fail so miserably? The nation shows no hesitation in pointing their fingers at one direction when it comes to the country's failure in sports, most feel the government is to blame and the lack of qualified coaches is conceivably the biggest problem (Gutierrez, 2012).

In the recent Batang Pinoy 2016 National Championship held at Davao del Norte Sports Complex, Tagum City, athletes from UM Tagum College participated on the said activity which they represent Tagum City and Davao del Norte. In the final tally, Baguio City got 55 gold, 41 silver, 41 bronze with a grand total of 137, Cebu City got 43 gold, 31 silver, 65 bronze with a grand total of 106, Davao City got 35 gold medals, 44 silver, 65 bronze with a grand total of 144 while Tagum City got only 3 gold, 4 silver and 16 bronze with a grand total of 23 (Batang Pinoy Page, 2016). It is for this reason that the researcher was compelled to conduct a study to determine which domain of coaching behavior of coaches significantly predicts athlete satisfaction.

Statement of the problem - This study aimed to determine which domain in the coaching behavior significantly predicts athlete satisfaction in UM Tagum College. More specifically, it sought answers to the following questions:

$>\quad$ What is the level of coaching behavior of coaches in terms of physical training and conditioning; technical skills; mental preparation; goal setting; competition strategies; and personal rapport?

$>\quad$ What is the level of athlete satisfaction in terms of training and instruction; personal treatment; team performance; and individual performance?

$>\quad$ Is there a significant relationship between coaching behavior of coaches and athlete satisfaction?

$>$ Which domain in the coaching behavior of coaches significantly predicts athlete satisfaction?

Hypotheses - The following null hypotheses were tested at 0.05 level of significance. 1) There is no significant relationship between coaching behavior and athlete satisfaction, and 2) There is no domain in the

66 Consortia Academia Publishing (A partner of Network of Professional Researchers and Educators) 
coaching behavior significantly predicts athlete satisfaction.

\section{Literature review}

\subsection{Athlete Satisfaction}

An individual's perception of his or her satisfaction has been posited to be important in sport. Although the construct of athlete satisfaction has been interest to researchers, few studies have addressed the underlying standards and processes that determine whether an athlete perceives his or her experience as being satisfying or dissatisfying. Individual satisfaction and performance should be naturally linked. For example, a more satisfied athlete might be expected to exert more effort and persistence in the face of competition (Bray, 2009). Moreover, Maday (2010) stated that without satisfaction, athletes would turn to other sources for potential success and enjoyment. Satisfaction in sport has been studied extensively in combination with several variables, mostly leadership. Several scholars in sport psychology have included athlete satisfaction as an antecedent or outcome variable in their work. Studies based on the multidimensional model of leadership have been largely concerned with linking leadership dynamics with athlete satisfaction.

Training and Instruction. Athlete satisfaction is regarded as the quality of the management in the organization as perceived by the athlete. It is positive effect resulting from a complex evaluation of structure, processes, and outcome associated with the athletic experience. Athlete satisfaction is derived from the physical, psychological, and environmental aspects that are associated with athletes. The level of satisfaction is an indicator of the athlete's feelings about the sport team environments (Sriboon, 2011). Furthermore, Beller (2008) mentioned that coaches can motivate players toward teamwork when they provide solid instruction and training, encourage a democratic and fair environment and offer support via positive feedback. However, it's important for coaches to be consistent, and if they're working with other coaches, the coaching team must work as a cohesive unit.

In addition, Saleh (2012) pointed out that training and instruction dimension measures coaching behavior aimed at improving the athlete's performance by emphasizing and facilitating hard and strenuous training; instructing them in the skills, techniques, and tactics of the sport; clarifying the relationship among the members; and instructing and coordinating the member's activities. Likewise, coaching behaviors in practice, at games, and away from the sport have strong influences on players and can impact both players' performances and continued participation. Some researcher wrote that sport performance would be positively affected if coaches adapted their behaviors to comply with athletes' preferences, noted that player satisfaction in sport is often a direct result of coaching behavior, not successful team performance (Abernathy, 2012).

Personal Treatment - It is possible that satisfaction with social support might be more important than the level, type, or number of supports that student-athletes receive. It appears that a person's satisfaction with social support is related to increased emotional and physical well-being. For example, athletes' satisfaction with their social support has been associated with lower levels of mood disturbance (Green et al., 2014). Additionally, resources such as acceptance, confidence, outlet for self-disclosure, and problem-solving ability gained from student-athletes' support systems can lead to life. Further, increased social support can lead to less physical and emotional exhaustion, which may have a positive effect on overall functioning. As a result, the social support that student-athletes receive from other athletes, their coaches, athletic staff, and even parents might be positive for their overall well-being when they consider the support to be at a satisfactory level (Gordon, 2007).

Similarly, the dimension of social support, which is a humanistic style, satisfies the interpersonal needs of athletes or clients by remaining sensitive to them and helping them with their personal problems. A high degree of emotional intelligence, specifically empathy or having the ability to understand the emotional makeup of people and treating them according to their emotional reactions, will be required to effectively carry out this dimension (Goleman, 2012). Also, Zhang (2005) mentioned that positive feedback is based upon a behaviorist 
approach and is also known as positive reinforcement. Coaches and personal trainers will compliment or reward their athletes or a client on their successes, which maintains motivational levels. The athlete or client will be rewarded for a good performance or effort.

Meanwhile, athletes on winning teams were more satisfied with their coach's strategy and relationship with their coach. They found that winning coaches displayed transformational leadership behaviors (vision, inspiration, technical instruction), the two positive dimensions of transactional leadership (positive feedback) and decision making (active management) lead to more satisfied athletes in terms of motivation, relationship with their coach, and their performance (Cho, Lee, \& Magnuesen, 2010). Further, Smith and Kendall (2012) pointed out that open dialogue between the coach and athlete is associated with greater degrees of athlete satisfaction and better performances. Good performances should be praised, with the coach providing insightful information on that performance. A poor performance should not be openly criticized; instead, the coach should highlight any good aspect of the performance.

Team performance - Athlete satisfaction towards team defines as individual satisfaction with the team behavior (e.g with team performance, team task contribution, team social contribution and team integration). Team behavior connotes collective action made by the team. Team is defined as two or more individuals who shared a common goal. Collaboration and sense of belonging is needed in the team in order to have similar goal (Banack, 2012). Sense of belonging to the team is pertinent for athlete to perceive as it may contribute towards athlete's satisfaction and motivation. Previous study stated that acceptance level of individual athlete within the group is important to determine the outcome. It measures each individual in the team contribute an effort to fulfill the task. Person who is satisfied with the team is more likely to be motivated (Dundee, 2011). Moreover, leadership is a process by which one individual is able to guide a group of other individuals toward a collective goal, action or accomplishment. Being, such the coaches has to plan out and shared the team set up, goal and all aspect related to athlete satisfaction (Chemors, 2012).

Individual performance - Athlete's performance depends on the coaches' behavior. It shows that the coach is the most important element for athlete to perform well. It depends on the situation where the coach's action will affect athlete satisfaction during training or competition thus impact the result of athlete's performance. Previous researched have shown there are various factors that can make athletes to perform well such as coach's competency, coach's leadership and coach-athlete relationship (Jowett, 2012). More so, athlete who is intrinsically motivated may be affected by the feeling of satisfaction on their teammates. Intrinsic motivation refers to inner enjoyments and willingness that rise in the heart as for the task given. There is evidence said that intrinsic motivation is given commitment in whatever person's do or actively participated in the event for their own satisfaction. This shows that individual will have their own initiative without any external forces, and it is important for athlete to intrinsically motivate in sport involvement (Lei, 2011).

In addition, intrinsic motivation describes an inner force in completing task. However, even though this motivation is come from the inner force, but to achieve it one must deal with external event. Studies on sport have mentioned that interaction and communication between athletes, teammates and coaches are always existed. Therefore, there is a possibility that athlete's satisfaction on teammates may influence on athlete's intrinsic motivation (Wiersma, 2008). McGuire (2013) mentioned that individual satisfaction in the team can occur when one satisfied with the guidance provided by leader. Previous studies had shown that athlete possess leader behavior has significant influence on group level outcome (e.g, performance and satisfaction). Moreover, as a leader he/she plays a fundamental role for team's success. Study had shown that individual contribution on the team has a significant influence with satisfaction which later brings the positive outcome.

\subsection{Coaching Behavior}

To achieve improvement in athletic performance, it may be necessary for a coach to engage in a variety of coaching behaviors to which all athletes may respond. Certain coaching behaviors may be more productive than 
others. What may be an appropriate coaching behavior to one athlete may be an ineffective approach for another. While coaching team sports, coaches must take into consideration the different needs and preferences from individual athletes within the team and at the same time keep the team focused as one unit (Tinning, 2004). More so, an important and successful leadership factor for a coach is to utilize proper coaching behavior within training instruction that addresses all the individual athletes and at the same time maintain team cohesion. A prudent and intelligent coach will utilize leadership behavior that will help to improve the athlete's performance (Bollen, 2010).

Hoyle (2011) discussed that it is important for the coach to be aware of the coaching preferences of his or her athletes in order to provide satisfactory experiences and improvement in athletic performance, yet at the same time have cohesiveness amongst the entire team. Kilburg (2008) pointed out that the qualities of a coach must have a successful coaching outcome, which include being respectful, considerate, predictable, courteous, empathetic, friendly, tactful, non-defensive, knowledgeable, and skillful. At times the coach may need to be tender and nurturing or even playful when challenging a client to grow, explore, or be curious. The coach is also responsible for providing knowledge, skills, and technical assistance for the client's professional and personal growth.

Physical Training and Conditioning. Physical training is utilized to bolster the athlete's or client's skill set. Here a strength coach may help refine an athlete's Olympic lifting technique or a personal trainer may guide his client through some mobility drills or flexibility exercises that were just introduced. This dimension focuses on explaining the techniques of the exercises and the tactics of the drills, provides rationale as to why these new concepts are being implemented and clarifies training priorities to be worked on (Mageau, 2012). Ewing (2013) revealed that quality training or practicing provide opportunities for coaches to display their knowledge and skills to help prepare athletes for competition. Training involves the provision of tuition about physical, tactical, technical, and mental aspects of the sport. Although some coaches also teach their athletes psychological skills (such as mental imagery or relaxation techniques) to help them learn and perform new skills, and effective strategies to improve their self-confidence and regulate.

Rosandich (2011) stated that as sport evolved into organized activity, coaches began working more closely with athletes on sport skill development. Education and training programs have been created for athletes to develop methods and strategies for achieving peak performance. Athletes have sought to acquire the skills and knowledge of sport in order to become "champions". Moreover, athletes of all ages are directed by coaches, giving them a significant impact on the athletes. The coach's role is considered to be highly complex process. Coaches in most settings must complete a variety of tasks such as planning practices and game strategies, organizational tasks and mentoring athletes which does in fact include more than teaching fundamental skills and tactics. Thus, the coach and the athlete interaction is unique with the goal to bring about successful performance outcomes and satisfaction (Anshel, 2012).

Technical Skills - The coach-athlete relationship is also influenced by the uniqueness of each athlete. Every athlete is different from one another from male to female; from individual sport athletes to team sport athletes, each athletes requires different coaching behaviors than another athlete. This uniqueness can influence the kind of motivational tactics a coach uses toward a team or player, as well as how the coach-athlete relationship is developed (Horn, 2010). Marshall (2012) pointed out that coaches must be exceptional communicators with their athletes in order to be effective teachers. The ability to communicate is a critical component in becoming a successful coach and developing elite athletes. It is the foundation upon which coaches build their team. Coaching without effective communication is like trying to play basketball without a ball; it just is not a successful endeavor. Moreover, coaches have the opportunity to teach their players many life skills and effective communication may be the most valuable one, yet time is not always in the coach's favor. From limits on practice time or set times for half-time and timeouts during athletic competition, coaches encounter several constraints which can limit the time allowed to convey messages to their players. Therefore, coaches should organize their messages efficiently in hopes of developing positive relationships with players (Weinberg, 2011). 
Cassidy (2012) stressed out that communicating effectively will allow coaches to teach their athletes the necessary sport skills to produce peak performance and increase the possibility of having a successful athletic program. Players need to feel that their coach cares about them as a person; not just as an athlete who can help them win games and establish a successful athletic program. Additionally, one of the primary roles of the coach is teaching. Teaching means helping athletes learn physical skills and improve their athletic performance. The coach has the responsibility to develop athletes from the beginning stage of learning to becoming skilled athletes. Like all training, the process of learning skills is a long term process (Robinson, 2010).

Mental Preparations - An important aspect of a good coach-athlete relationship is the coach's ability to understand each athlete as an individual and to tailor his/her coaching style and attention to suit those need. Coaches who are not satisfied with their coaching process may result in bad coaching or coaching process, and players' effectiveness will consequently be negatively impacted (Dieffenbachia, 2009). Sherman (2011) revealed that coaching behavior can result from the enforced organizational demands. The coaching behavior preferred by the trainees refers mainly to preferences concerning instructions and guidance given during the training process, the offered social support and the type and frequency of the provided feedback. Brotman et al. (2010) mentioned that leading up to a competition is important to provide athletes with the mental tools so that they can learn to manage their own performance and create their optimal level of mental readiness. Athletes can then use the tools to develop their personal routines and plans for achieving mental readiness for competition.

Goal Setting - Goal setting is found to be effective in improving group performance. The extent to which athletes engage in goal setting and the effectiveness on mental training elements is beneficial to examine. It is a component of mental skills training found to be effective for enhancing commitment, effort, self-confidence, and perseverance and motivation of athletes although its origins lie in organization settings. Accepting the goals that are set is necessary for an athlete to be committed to his or her goals and positively affect performance (Arrends et al., 2012). The coach, along with the players, must set obtainable yet demanding team goals. Strong leadership becomes a moot point if the players are uninterested in the mission and goals. Coaches must develop a strong rapport which involves trust and confidence on both ends. Leaders are there to coach, direct and nudge players in the direction of the goals (Williams, 2009). Case (2006) stressed out that leaders have a strong ability to pass their intensity along to their athletes. They are always in the game right along with the players. A leader guides a team, not rules a team. He or she charts a course, gives direction and develops the social and psychological environment.

Competition Strategies - Coaching philosophy must specify the importance you place on character development. Competition can play a valuable role in helping athletes develop positive character traits that will help them succeed in future endeavors. But competition does not automatically generate positive character traits, and, regrettably, competing in sport sometimes detracts from character development (Maehr, 2009). However, moral reasoning and good sporting behavior seem to decline as athletes' progress to higher competitive levels, in part because of the increased emphasis on winning. Thus winning can be a double-edged sword in teaching character development (Stoll, 2010). Moreover, coaches have some level of responsibility for all aspects of their athletic program. Coaches need to be concerned about the welfare of their players and the maintenance of athletic equipment and facilities. A substantial amount of time is required to assess sport facilities and equipment in order to prevent injury to sport participants during competition and ensure that all equipment used is safe and appropriate for the participants involved in the sport activity (Scott, 2011).

In addition, Tiffan (2012) stated that strategy in athletic competition using the art of war, knowledge is what enables the good player for hints of weaknesses in his opponent. This is especially true when competition has high stakes. Christensen (2011) mentioned that coaches are very important segment of sport because they are the first component to a college athlete's career. Coaches they are the ones that call the plays, make the line-ups and determine playing time for that athlete. Many things go into being a great coach including philosophy, tactics, communication, strategy, and knowledge. Great coaching is very objective but regardless, great and poor coaches have specific behaviors. All of these influence the behaviors in which the coach exhibits. Consequently, 
athletes like coaches, have specific behaviors they prefer or expect from their coaches. Meeting or exceeding the expectations and preferences is an integral part of coaching athletes. Figuring out what kind of behaviors athletes prefer significantly help or hinder the development of the coach-athlete relationship (Mallett, 2005).

Personal Rapport - The coach-athlete relationship is related to the positive and negative behaviors that a coach exhibits. Positive behaviors are those behaviors that are supportive and emotionally composed such as a coach recognizing an athlete's improvements in their physical appearance after coming back from training in the off-season. The negative behaviors a coach can exhibit are ones that are "distractive and disruptive" such as a coach ridiculing and making an athlete feel awkward when he or she is working out (Lumer, 2009). Carnegie (2011) stated that one must be a good motivator and have the gift for verbal persuasion to get athletes to "buy in" to the fact that hard work does pay off and that the pursuit of excellence, while a tough journey, is a worthwhile one. One cannot take motivation for granted. Even the players who are always motivated can use some outside motivation from coaches. They must be encouraged as people and as players.

Madrigal et al. (2013) discussed that to get the most out of each player and make the team experience a positive one, one must understand the individuality of players and the dynamics of group interaction. It is essential to know members well enough to be able to assess their strengths and weaknesses and use them to their fullest potential within the context of the team. Systematic delegation getting the right players doing the right job is vital on teams. For example, the selection of the right person to be team captain can be important. This is why it is so important for a coach to get to know each of the players as well as possible. Bob (2012) stated that coaches should develop strong relationships with their athletes and to take on the role of friend and mentor. This process involves being a positive role model, discussing problems, sharing successes, offering support when needed, and even providing counselling when necessary. This aspect of coaching can have a strong positive or negative effect on the athlete and affects their feelings of satisfaction with the coach-athlete relationship. Pyke (2011) a coach has to assimilate a vast amount of information and scientific data about their sport, and translate it into practical coaching and training programs. The success or failure of this process relies heavily on the coach's experience, availability of resources, knowledge of the event or sport, and their relationship with the athletes that they are coaching. By understanding the scientific principles that surround their sport, a well-designed training program can be developed that will help an athlete reach their full potential.

All authors mentioned above discussed the coaching behavior of coaches and athlete satisfaction. The coach plays a pivotal role in athletes' sport execution, and various coach behaviors can affect athletes positively or negatively. The coach is a meaningful person in the lives of athletes and the role they play is vital in the athlete's sport experience. But the coach is also responsible for the guidance of the athlete in life and their chosen sport. An athlete who is more satisfied will put out more effort and persistence during competition. Thus, satisfaction has been posited to be important in sport.

\subsection{Theoretical and conceptual framework}

This study is anchored on the concept of Terry (2001) who examined coaching behaviors and athlete satisfaction in elite athletes. These studies have effectively indicated that the behaviors demonstrated by the coach are important determinants of athlete. The concept was supported by Riemer and Chelladurai (1998), satisfaction is an integral part of sport participation and enjoyment. Satisfaction most salient for a particular situation such as training and instruction satisfaction, personal treatment satisfaction, team performance satisfaction, and individual performance satisfaction. Carron (2002) included satisfaction as both as antecedent (i.e, personal factor) and outcome (i.e, individual outcomes) in his model of cohesion. Satisfaction has also been considered as predicted outcome of a coach's efficacy. Blanchard (2009) coach-athlete interactions have been shown to influence athletes' perceptions of their sport satisfaction and enjoyment. Athlete satisfaction is crucial for performance and self-determined behaviors and highly influenced by the behaviors of the coach.

Baker et al. (2003), stated that the coach can have a profound impact on athlete satisfaction regardless of the 
level of sport involvement. Coaching behavior such as mental preparation, technical skills, goal setting, physical training and conditioning, competition strategies and personal rapport. Figure 1 shows the conceptual paradigm of the study. Coaching behavior has six indicators namely: physical training and conditioning- in this study, it is operationally defined as having a yearly training plan and providing structured workouts; technical skills- in this study, it referred to the use of positive reinforcement and feedback; mental preparation- in this study, it referred to a specific behaviors included providing advice on staying positive and focused; goal setting- it referred to setting long and short-term goals; competition strategies- in this study, it referred to the specific behaviors such as ensuring needs are met at competition site and maintaining consistency during competitions; and personal rapport- it referred to the specific behaviors in developing a sense of trust and confidentiality.

The athlete satisfaction has four indicators namely: training and instruction- in this study, it is operationally defined as the satisfaction with the training and instruction provided by the coach; personal treatment- in this study, it referred to the satisfaction of athletes that includes social support and positive feedback from the coach; team performance- in this study, it referred to an individual's satisfaction with his/her team's level of performance; and individual performance- in this study, it referred to an individual's satisfaction with his/her own task performance.

Independent Variable

Dependent Variable
Athlete Satisfaction

- Training and Instruction

- Personal Treatment

- Team Performance

- Individual Performance

Mental preparation

- Goal setting

- Competition strategies

- Personal rapport

Figure 1. Conceptual Paradigm Showing the Variables of the Study

\section{Methodology}

Research Design - The study is a quantitative non experimental method employing correlational approach. Non-experimental research method is used to describe variables and its relationship wherein the researcher cannot control or alter the predictor variable or subjects, but instead, relies on interpretation, observation or interactions to come to a conclusion (Kowalzyk, 2015). To determine the relationship of the two variables, a survey was conducted in a form of questionnaires.

Research Subjects - The respondents of this research undertaking involved the athletes from high school and college in UM Tagum College. The study was focused on the relationship of coaching behavior of coaches and athlete satisfaction from different events. In selecting the respondents, the researcher used simple random sampling method. The sample size was determined by the use of Slovin's formula.

Research Instruments - The researcher utilized the two standardized questionnaires to measure the independent variable and dependent variable. The standardized questionnaires were presented to the thesis adviser for comments, recommendations and endorsement to a panel of experts for validation. Comments and correction from the evaluators were sought to refine the final instrument. To measure coaching behavior, the researcher used the Coaching Behavior Scale for Sport adapted from Coté et al. (1999) with five (5) items for each indicator namely: physical training and conditioning (5), technical skills (5), mental preparation (5), goal setting (5), competition strategies (5), and personal rapport (5). This gives a total of thirty (30) items. The researcher questionnaires used the scale that ranges from 1 to 5 .

72 Consortia Academia Publishing (A partner of Network of Professional Researchers and Educators) 
Athlete Satisfaction Questionnaire adapted from Riemer et al. (1998) was used to measure athlete satisfaction with four (4) items with five (5) choices given with corresponding descriptive value for each indicator namely: training and instruction (5), personal treatment (5), team performance (5) and individual performance (5).

\section{Table 1}

Distribution of respondents

\begin{tabular}{|c|c|c|}
\hline Sports Event & Population & Sample \\
\hline basketball & 35 & 21 \\
\hline beach volleyball & 12 & 7 \\
\hline baseball & 12 & 6 \\
\hline lawn tennis & 8 & 4 \\
\hline taekwondo & 16 & 10 \\
\hline track and field & 30 & 17 \\
\hline soccer football & 15 & 3 \\
\hline volleyball & 40 & 25 \\
\hline karatedo & 32 & 17 \\
\hline softball & 12 & 6 \\
\hline chess & 8 & 4 \\
\hline badminton & 20 & 11 \\
\hline table tennis & 10 & 5 \\
\hline sepak takraw & 24 & 14 \\
\hline dance sports & 16 & 8 \\
\hline swimming & 40 & 19 \\
\hline & 331 & 179 \\
\hline
\end{tabular}

Data Gathering Procedure - In this section the researcher followed the steps in conducting the study.

$>\quad$ Seeking permission to conduct the study. Permission and approval were sought from the Dean of the Graduate School. After the approval of the request, the researcher wrote a letter asking permission to conduct the study which was addressed to the sports coordinator of UM Tagum College.

$>$ Administration and retrieval of questionnaire. When the approval to conduct the study was granted, the researcher then personally conducted the sets of survey questionnaires to ensure complete data to be gathered.

$>$ Checking, collating and processing of data. Each questionnaire was collected and checked. The responses and ratings were collated and subjected with the appropriate statistical tools to obtain the results of the study. The results were analyzed to answer the problems raised in the first chapter of the study.

Statistical Treatment - For the interpretation of the collected data, the following statistical tools were used:

$>$ Mean. This is a statistical tool used to determine if there is a correlation between variables. This was used to test the difference between coaching behavior of coaches and satisfaction of athletes.

$>$ Pearson $r$. This is a statistical tool used to determine if there is correlation between variables. It was used to measure the significant relationship between coaching behavior of coaches and athlete satisfaction in UM Tagum College.

$>\quad$ Regression analysis. It is a statistical process for estimating the relationship among variables. This tool will be used in this study to determine relationship between coaching behavior of coaches and athlete satisfaction.

\section{Results and discussions}

In this section, the researcher presents, analyzes and interprets the data gathered in textual and tabular forms. 


\section{Level of coaching behavior of coaches in terms of physical training and conditioning}

The level of coaching behavior of coaches in terms of physical training and conditioning is presented in Table 2. The term Providing athletes a physically challenging conditioning program, gets the highest mean of 4.23 with the description of high. Providing athletes with a plan for physical preparation, with the average weighted mean of 4.19. Ensuring that training facilities and equipment are organized, gets average weighted mean of 3.98, with the description of high. Providing athletes with structured training sessions, with the average weighted mean of 4.01. Providing athletes with an annual training program, gets the lowest average weighted mean of 3.74, with the description of high. All items get the same description of high which means that of coaching behavior of coaches in terms of physical training and conditioning is observed in most occasions. This is supported by Rosandich (2011) stated that as sport evolved into organized activity, coaches began working more closely with athletes on sport skill development. Education and training programs have been created for athletes to develop methods and strategies for achieving peak performance. Athletes have sought to acquire the skills and knowledge of sport in order to become "champions".

\section{Table 2}

Level of coaching behavior of coaches in terms of physical training and conditioning

\begin{tabular}{lcc}
\hline \multicolumn{1}{c}{ Items } & Mean & Description \\
\hline 1. Providing athletes a physically challenging conditioning program. & 4.23 & High \\
2. Providing athletes with a plan for physical preparation. & 4.19 & High \\
3. Ensuring that training facilities and equipment are organized. & 3.98 & High \\
4. Providing athletes with structured training sessions. & 4.01 & High \\
5. Providing athletes with an annual training program. & OVERALL MEAN & 3.74 \\
\end{tabular}

\section{Level of coaching behavior of coaches in terms of technical skills}

Table 3 points out the level of coaching behavior of coaches in terms of technical skills. Providing athletes with advice while I'm performing a skill, gets the highest average weighted mean of 4.25, followed by Providing athletes with feedback that helps me improve my technique, and Making sure I understand the techniques and strategies I'm being taught, with the same average weighted mean of 4.21. Using verbal examples that describe how a skill should be done, posted the mean of 4.18. The mentioned items get the same description of high. Providing visual examples to show how a skill should be done, gets the lowest average weighted mean of 4.08, with the description of high. The overall mean of 4.19 attested that the level of coaching behavior of coaches in terms of technical skills is high. This is supported by Robinson (2010) that one of the primary roles of the coach is teaching. Teaching means helping athletes learn physical skills and improve their athletic performance. The coach has the responsibility to develop athletes from the beginning stage of learning to becoming skilled athletes. Like all training, the process of learning skills is a long term process.

Table 3

Level of coaching behavior of coaches in terms of technical skills

\begin{tabular}{lcc}
\hline \multicolumn{1}{c}{ Items } & Mean & Description \\
\hline 1. Providing athletes with advice while I'm performing a skill. & 4.25 & High \\
2. Providing athletes with feedback that helps me improve my technique & 4.21 & High \\
3. Providing visual examples to show how a skill should be done. & 4.08 & High \\
4. Using verbal examples that describe how a skill should be done. & 4.18 & High \\
5. Making sure I understand the techniques and strategies I'm being taught. & 4.21 & High \\
\end{tabular}

\section{Level of coaching behavior of coaches in terms of mental preparation}

Table 4 presents the level of coaching behavior of coaches in terms of mental preparations. The third item, Providing advice on how to stay confident about own abilities, gets the highest mean of 4.32 with the descriptive equivalent of high. It is followed by the second item, Providing advice on how to be mentally tough, has posted 
the mean of 4.29 with the descriptive equivalent of high which indicates that the coaching behavior of coaches is observed in most occasions. Fifth item, Providing advice on how to stay focused, has posted the mean of 4.25. The same average weighted mean of 4.28 is on the first item, Providing advice on how to perform under pressure, and the fourth item, Providing advice on how to stay positive about myself, with the descriptive equivalent of high. The overall mean of 4.28 has suggested that level of coaching behavior of coaches in terms of mental preparation is high. This is supported by Brotman et al. (2010) that leading up to a competition is important to provide athletes with the mental tools so that they can learn to manage their own performance and create their optimal level of mental readiness. Athletes can then use the tools to develop their personal routines and plans for achieving mental readiness for competition.

\section{Table 4}

Level of coaching behavior of coaches in terms of mental preparation

\begin{tabular}{|c|c|c|}
\hline Items & Mean & Description \\
\hline 1. Providing advice on how to perform under pressure. & 4.28 & High \\
\hline 2. Providing advice on how to be mentally tough. & 4.29 & High \\
\hline 3. Providing advice on how to stay confident about own abilities. & 4.32 & High \\
\hline 4. Providing advice on how to stay positive about myself. & 4.28 & High \\
\hline 5. Providing advice on how to stay focused. & 4.25 & High \\
\hline OVERALL MEAN & 4.28 & High \\
\hline
\end{tabular}

\section{Level of coaching behavior of coaches in terms of goal setting}

Table 5 demonstrates the level of coaching behavior of coaches in terms of goal setting. The table shows that all the items have the description of high. The first item, Helping athletes identify strategies to achieve my goals, gets the highest average weighted of 4.25. It is followed by the fourth item, Helping athletes set long-term goals, which has the mean of 4.09. Helping athletes identify target dates for attaining my goals, gets an average weighted mean of 4.06. Providing support to attain goals, has posted the mean of 4.04 and third item, Monitoring athlete's progress toward their goals, gets the lowest mean of 3.96. The overall mean of 4.08 entails that the level of coaching behavior of coaches in terms of goal setting is high. This means that the coaches help and monitor the athlete's in achieving goals as often as possible. This is supported by Case (2006) that leaders have a strong ability to pass their intensity along to their athletes. They are always in the game right along with the players. A leader guides a team, not rules a team. He or she charts a course, gives direction and develops the social and psychological environment.

\section{Table 5}

Level of coaching behavior of coaches in terms of goal setting

\begin{tabular}{|c|c|c|}
\hline Items & Mean & Description \\
\hline 1. Helping athletes identify strategies to achieve my goals. & 4.25 & High \\
\hline 2. Helping athletes identify target dates for attaining my goals. & 4.06 & High \\
\hline 3. Monitoring athletes progress toward their goals. & 3.96 & High \\
\hline 4. Helping athletes set long-term goals. & 4.09 & High \\
\hline 5. Providing support to attain goals. & 4.04 & High \\
\hline OVERALL MEAN & 4.08 & High \\
\hline
\end{tabular}

\section{Level of coaching behaviors of coaches in terms of competition strategies}

Table 6 highlights the level of coaching behavior of coaches in terms of competition strategies. All given items have the description of high. The first item, Helping athletes focus on the process of performing well, gets the highest average weighted mean of 4.25 , followed by the fifth item, Showing confidence to athletes ability during competitions, with the average weighted mean of 4.22 . Third item, Dealing with problems athletes might experience at competition, has posted the mean of 4.07, followed by the second item, Preparing athletes face a variety of situations in competition, with the mean of 4.05. The fourth item, Ensuring that facilities and equipment are organized for competition, gets the lowest mean of 3.82. The overall mean of 4.08 has suggested that the level of coaching behavior of coaches in terms of competition strategies is high. This is supported by 
Scott (2011) that coaches have some level of responsibility for all aspects of their athletic program. Coaches need to be concerned about the welfare of their players and the maintenance of athletic equipment and facilities. A substantial amount of time is required to assess sport facilities and equipment in order to prevent injury to sport participants during competition and ensure that all equipment used is safe and appropriate for the participants involved in the sport activity.

\section{Table 6}

Level of coaching behavior of coaches in terms of competition strategies

\begin{tabular}{|c|c|c|}
\hline Items & Mean & Description \\
\hline 1. Helping athletes focus on the process of performing well. & 4.25 & High \\
\hline 2. Preparing athletes face a variety of situations in competition. & 4.05 & High \\
\hline 3. Dealing with problems athletes might experience at competition. & 4.07 & High \\
\hline 4. Ensuring that facilities and equipment are organized for competition & 3.82 & High \\
\hline 5. Showing confidence to athletes ability during competitions & 4.22 & High \\
\hline OVERALL MEAN & 4.08 & High \\
\hline
\end{tabular}

\section{Level of coaching behavior of coaches in terms of personal rapport}

Table 7 specifies the level of coaching behavior of coaches in terms of personal rapport. As shown on the table, all the given items have the same description of high. The fifth item, Maintaining confidentiality regarding athlete's personal life, gets the highest average weighted mean of 4.47 , followed by the first item, Showing understanding for athletes as a person, with the mean of 4.44. The second item, My coach is a good listener, has posted the mean of 4.36, followed by the fourth item, Demonstrating concern for my whole self, with the average weighted mean of 4.12. The third item, Is easily approachable about personal problems athletes might have, gets the lowest mean of 4.07. The overall mean of 4.29 has entailed that the level of coaching behavior of coaches in terms of personal rapport is high. This is supported by Bob (2012) that coaches should develop strong relationships with their athletes and to take on the role of friend and mentor. This process involves being a positive role model, discussing problems, sharing successes, offering support when needed, and even providing counselling when necessary. This aspect of coaching can have a strong positive or negative effect on the athlete and affects their feelings of satisfaction with the coach-athlete relationship.

\section{Table 7}

Level of coaching behavior of coaches in terms of personal rapport

\begin{tabular}{lcc}
\hline \multicolumn{1}{c}{ Items } & Mean & Description \\
\hline 1. Showing understanding for athletes as a person. & 4.44 & High \\
2. Is a good listener. & 4.36 & High \\
3. Is easily approachable about personal problems athletes might have. & 4.07 & High \\
4. Demonstrating concern for my whole self. & 4.12 & High \\
5. Maintaining confidentiality regarding athlete's personal life. & 4.47 & High \\
OVERALL MEAN & 4.29 & High \\
\hline
\end{tabular}

\section{Summary on the level of coaching behavior of coaches}

Table 8 indicates the summary on the level of coaching behavior of coaches. Among the six indicators, personal rapport gets the highest average weighted mean of 4.29, 4.28 for mental preparation, 4.19 for technical skills, 4.08 for goal setting and competition strategies and the lowest mean of 4.03 for physical training and conditioning. The overall mean of 4.16 means that the level of coaching behavior of coaches is high. This would mean that, the coaching behavior of coaches is experience most of the time specifically personal rapport in which coaches showing understanding for athlete as a person and easily approachable whenever there is a personal problem. This is supported by Kilburg (2008) that the qualities of a coach must have a successful coaching outcome, which include being respectful, considerate, predictable, courteous, empathetic, friendly, tactful, non- defensive, knowledgeable, and skillful. At times the coach may need to be tender and nurturing or even playful when challenging a client to grow, explore, or be curious. The coach is also responsible for providing knowledge, skills, and technical assistance for the client's professional and personal growth. 
Table 8

Summary on the level of coaching behavior of coaches

\begin{tabular}{|c|c|c|}
\hline Indicator & Mean & Description \\
\hline Physical training and conditioning & 4.03 & High \\
\hline Technical skills & 4.19 & High \\
\hline Mental preparation & 4.28 & High \\
\hline Goal setting & 4.08 & High \\
\hline Competition strategies & 4.08 & High \\
\hline Personal rapport & 4.29 & High \\
\hline OVERALL MEAN & 4.16 & High \\
\hline
\end{tabular}

\section{Level of athlete satisfaction in terms of training and instruction}

Table 9 declares the level of athlete satisfaction in terms of training and instruction. The third item, The coach's teaching of the tactics and technique of my position, gets the highest average weighted mean of 4.11 with the description of very satisfied. The first item, The training I received from the coach this school year, has posted the mean of 4.08, followed by the second item, The instruction I have received from the coach this school year, with the mean of 3.97. The fifth item, The training schedule provided by the coach this school year, has posted the mean of 3.95 followed by the fourth item, The facilities and equipment provided by the coach during training session, which gets the lowest average weighted mean of 3.71. The overall mean of 3.97 has entailed that the level of athlete satisfaction in terms of training and instruction is very satisfied. This is supported by Saleh (2012) that training and instruction dimension measures coaching behavior aimed at improving the athlete's performance by emphasizing and facilitating hard and strenuous training; instructing them in the skills, techniques, and tactics of the sport; clarifying the relationship among the members; and instructing and coordinating the member's activities.

\section{Table 9}

Level of athlete satisfaction in terms of training and instruction

\begin{tabular}{|c|c|c|}
\hline Items & Mean & Description \\
\hline 1. The training I received from the coach this school year. & 4.08 & Very Satisfied \\
\hline 2. The instruction I have received from the coach this school year & 3.97 & Very Satisfied \\
\hline 3. The coach's teaching of the tactics and technique of my position & 4.11 & Very Satisfied \\
\hline 4. The facilities and equipment provided by the coach during training session & 3.71 & Very Satisfied \\
\hline 5. The training schedule provided by the coach this school year. & 3.95 & Very Satisfied \\
\hline OVERALL MEAN & 3.97 & Very Satisfied \\
\hline
\end{tabular}

\section{Level of athlete satisfaction in terms of personal treatment}

Table 10 conveys the level of athlete satisfaction in terms of personal treatment. The fourth item, My coach's loyalty towards me, gets the highest mean of 4.13 with the description of very satisfied. The second item, The friendliness of the coach towards me, gets the average weighted mean of 4.09 followed by the fifth item, The extent to which the coach is behind me, has posted the mean of 4.08. The first item, The recognition I received from my coach, with the mean of 4.04 followed by third item, The level of appreciation my coach shows when I do well, which gets the lowest average weighted mean of 4.02. The overall mean of 4.07 has entailed that the level of athlete satisfaction in terms of personal treatment is very satisfied. This is supported by Smith \& Kendall (2012) that open dialogue between the coach and athlete is associated with greater degrees of athlete satisfaction and better performances. Good performances should be praised, with the coach providing insightful information on that performance. A poor performance should not be openly criticized; instead, the coach should highlight any good aspect of the performance. 


\section{Table 10}

Level of athlete satisfaction in terms of personal treatment

\begin{tabular}{|c|c|c|}
\hline Items & Mean & Description \\
\hline 1. The recognition I received from my coach. & 4.04 & Very Satisfied \\
\hline 2. The friendliness of the coach towards me. & 4.09 & Very Satisfied \\
\hline 3. The level of appreciation my coach shows when I do well. & 4.02 & Very Satisfied \\
\hline 4. My coach's loyalty towards me. & 4.13 & Very Satisfied \\
\hline 5. The extent to which the coach is behind me. & 4.08 & Very Satisfied \\
\hline OVERALL MEAN & 4.07 & Very Satisfied \\
\hline
\end{tabular}

\section{Level of athlete satisfaction in terms of team performance}

Table 11 points out the level of satisfaction of athletes in terms of team performance. As shown on the table all the given items have the same description of very satisfied. The fourth item, The extent to which teammates play as a team, has posted a highest average weighted mean of 4.36, followed by the fifth item, The team sense of fair play, with the mean of 4.28. Second item, The team's overall performance this school year, has posted a mean of 4.12, followed by the first item, The team's win/loss record this school year, which has posted a mean of 4.09. The third item, The extent to which the team has met its goal for this school year, has posted the lowest mean of 4.03. The overall mean of 4.18 has attested that the level of athlete satisfaction in terms of team performance is very satisfied. This is supported by Chemors (2012) that leadership is a process by which one individual is able to guide a group of other individuals toward a collective goal, action or accomplishment. Being, such the coaches has to plan out and shared the team set up, goal and all aspect related to athlete satisfaction.

\section{Table 11}

Level of athlete satisfaction in terms of team performance

\begin{tabular}{|c|c|c|}
\hline Items & Mean & Description \\
\hline 1. The team's win/loss record this school year. & 4.09 & Very Satisfied \\
\hline 2. The team's overall performance this school year. & 4.12 & Very Satisfied \\
\hline 3. The extent to which the team has met its goal for this school year & 4.03 & Very Satisfied \\
\hline 4. The extent to which teammates play as a team. & 4.36 & Very Satisfied \\
\hline 5. The team sense of fair play. & 4.28 & Very Satisfied \\
\hline OVERALL MEAN & 4.18 & Very Satisfied \\
\hline
\end{tabular}

\section{Level of athlete satisfaction in terms of individual performance}

Table 12 presents the level of athlete satisfaction in terms of individual performance. All the given items have the description of very satisfied. Fifth item, The dedication I give to work to achieve the same goals, gets the highest average weighted mean of 4.12, followed by the first item, The degree of which I have reached my performance goals during this academic year, has posted a mean of 4.06. The fourth item, The degree of which I did my best for the team, gets the mean of 4.01, followed by the third item, The improvement in my skill level thus far, with the mean of 3.99. The second item, The improvement in my performance over the previous year, gets the lowest average weighted mean of 3.94 .

\section{Table 12}

Level of athlete satisfaction in terms of individual performance

\begin{tabular}{|c|c|c|}
\hline Items & Mean & Description \\
\hline 1.The degree of which I have reached my performance goals during this academic year & 4.06 & Very Satisfied \\
\hline 2.The improvement in my performance over the previous year & 3.94 & Very Satisfied \\
\hline 3. The improvement in my skill level thus far. & 3.99 & Very Satisfied \\
\hline 4. The degree of which I did my best for the team. & 4.01 & Very Satisfied \\
\hline 5. The dedication I give to work to achieve the same goals. & 4.12 & Very Satisfied \\
\hline OVERALL MEAN & 4.02 & Very Satisfied \\
\hline
\end{tabular}

The overall mean of 4.02 has suggested that the level of athlete satisfaction in terms of individual performance is very satisfied. This is supported by McGuire (2013) that individual satisfaction in the team can 
occur when one satisfied with the guidance provided by leader. Previous studies had showed that athlete possess leader behavior has significant influence on group level outcome (e.g, performance and satisfaction). Moreover, as a leader he/she plays a fundamental role for team's success. Study had shown that individual contribution on the team has a significant influence with satisfaction which later brings the positive outcome.

\section{Summary on the level of athlete satisfaction}

Table 13 conveys the summary on the level of athlete satisfaction. Among the four indicators, team performance gets the highest mean of $4.18,4.07$ for personal treatment, 4.02 for individual performance and the lowest mean of 3.97 for training and instruction. The overall mean of 4.06 means that the level of athlete satisfaction is very satisfied. This would mean that athlete's level of satisfaction can be seen as a reflection of how well the athletic endeavor meets the athlete's own personal standards. A more satisfied athlete might be expected to exert more effort and determination in the face of competition. This is supported by Maday (2010) that without satisfaction, athletes would turn to other sources for potential success and enjoyment. Satisfaction in sport has been studied extensively in combination with several variables, mostly leadership. Several scholars in sport psychology have included athlete satisfaction as an antecedent or outcome variable in their work. Studies based on the multidimensional model of leadership have been largely concerned with linking leadership dynamics with athlete satisfaction.

\section{Table 13}

Summary on the level of athlete satisfaction

\begin{tabular}{|c|c|c|}
\hline Indicator & Mean & Description \\
\hline Training and instruction & 3.97 & Very satisfied \\
\hline Personal treatment & 4.07 & Very satisfied \\
\hline Team performance & 4.18 & Very satisfied \\
\hline Individual performance & 4.02 & Very satisfied \\
\hline OVERALL MEAN & 4.06 & Very satisfied \\
\hline
\end{tabular}

\section{Relationship between the coaching behaviors of coaches and athlete satisfaction}

Significant relationship between the coaching behavior of coaches and athlete satisfaction. The r-value of 0.82 indicates that there is a high positive correlation between the coaching behavior of coaches and athlete satisfaction. The coefficient of determination $\left(\mathrm{r}^{2}\right)$, which is 0.6690 means that $66.90 \%$ of the variation in the level of athlete satisfaction could be attributed to the variation in coaching behavior of coaches. The rest of the $33.10 \%$ is chance variation, which means further that the satisfaction of athletes could be attributed to other factors which are not included in this study such as the support from athletic department and administrators in terms of monetary sources to a team (budget) and the academic endeavour of athletes (academic support services). This would mean that the coach plays an essential role in athletes' sport execution, and various coach behaviors can affect athletes positively or negatively. Thus, the development of athletic talent is dependent upon quality coach. Likewise, the quality is often determined by how coaches behave in all aspects of their sport. Therefore, the coach is a meaningful person in the lives of athletes and the role they play is vital in the athlete's sport experience. This is supported by Blanchard (2009) that coach-athlete interactions have been shown to influence athletes' perceptions of their sport satisfaction and enjoyment. Athlete satisfaction is crucial for performance and self-determined behaviors and highly influenced by the behaviors of the coach.

\section{Regression analysis on the domains of coaching behavior that significantly predict athletes' satisfaction}

Regression analysis showed the domain in coaching behavior of coaches that significantly predict athlete satisfaction. The physical training and conditioning with the p-value of 0.02 , goal setting with p-value of 0.04 , technical skills, competition strategies and personal rapport with the same p-value of 0.00 , significantly predicts the athlete satisfaction. The p-value of each indicator is lower than the 0.05 level of significance except mental preparation with the p-value 0.14 which is greater than the 0.05 level of significance. It could also be noted that personal rapport significantly predicts more compared with other indicators considering the Beta coefficient of 
0.26 which is greater than the rest of the indicators. On the other hand, the p-value of 0.14 which is greater than the 0.05 level of significance means that the coaching behavior of coaches in terms of mental preparation does not significantly predicts athlete satisfaction. This would mean that mental preparation cannot predict the satisfaction of athlete in which it is least among the six coaching behavior. Even if the coaches provide advices on how to be mentally tough, positive and confident, it is still not significant for the athletes.

The overall findings match with the concept of Anshel (2012) that athletes of all ages are directed by coaches, giving them a significant impact on the athletes. The coach's role is considered to be highly complex process. Coaches in most settings must complete a variety of tasks such as planning practices and game strategies, organizational tasks and mentoring athletes which does in fact include more than teaching fundamental skills and tactics. Thus, the coach and the athlete interaction is unique with the goal to bring about successful performance outcomes and satisfaction.

\section{Summary of findings}

This section presents the summary of findings, the pertinent conclusions and recommendations given by the researcher based on the obtained results.

\subsection{Summary of Findings}

The following findings are enumerated and summarized as discussed in the preceding chapter.

$>$ Based on the result, the coaching behavior of coaches in UM Tagum College in terms of physical training and conditioning, technical skills, mental preparation, goal setting, competition strategies and personal rapport is observed in most occasions.

> The athlete satisfaction in UM Tagum College in terms of training and instruction, personal rapport, team performance and individual performance is much satisfied.

$>$ The null hypothesis is rejected, this means further that there is a significant relationship between the coaching behavior of coaches and athlete satisfaction.

$>$ The physical training and conditioning, technical skills, goal setting, competition strategies and personal treatment significantly predict athlete satisfaction.

\subsection{Conclusions}

Based on the findings of the study, the following conclusions are drawn:

$>$ The level of coaching behavior of coaches is high.

$>\quad$ The level of athlete satisfaction is very satisfied.

$>$ There is a significant relationship between coaching behavior of coaches and athlete satisfaction.

> Physical training and conditioning, technical skills, goal setting, competition strategies and personal rapport are domains in coaching behavior of coaches that significantly predict satisfaction of athletes. On the other hand, mental preparation does not significantly predict athlete satisfaction.

\subsection{Recommendations}

$>$ The administrator may provide full strength of facilities and equipment in order to have an effective and well organized training session.

The coaches will enhance existing annual training program for athletes. Training program has to be

80 Consortia Academia Publishing (A partner of Network of Professional Researchers and Educators) 
developed to meet the individual needs of the athlete and take into consideration many factors such as strength, weaknesses and objectives.

The coach could make a well-organized training schedule for the athletes in order to develop skills and achieved set goals. It is extremely important because it allows athletes to gain more knowledge of their sport as well as enabling them to learn about of having a healthy mind and body.

$>$ The athlete should stay positive and confident with their capability to perform effectively and efficiently during competition. It is important for the athlete to intrinsically motivate in completing a task.

The coaching behavior of coaches may strengthen and develop to achieve extremely satisfaction of the athletes.

Another study may be conducted to discover other predictor or factor that may predict athlete satisfaction.

\section{References}

Abernathy, R. (2012). Coaching preferences of athletes. McGraw Hill

Anshel, M. H. (2012). Sport psychology: From theory to practice (5th ed.). Benjamin Cummings.

Arrends, H., \& Klenk, C. (2012). The application of goal setting in sport. In S. Mellalieu \& S. Hanton (Eds.), Advances in applied sport psychology: A review (pp. 75-123). Routledge.

Baker, J., Yardley, J., \& Côté, J. (2003). Coach behaviors and athlete satisfaction in team and individual sports. International Journal of Sport Psychology, 34(3), 226-239.

Banack, H. (2012). Coach autonomy support, basic need satisfaction, and intrinsic motivation of paralympic athletes. Research Quarterly in Exercise and Sport, 82.

Batang Pinoy Page. (2016). Medal tally. Retrieved http://bp.2012.psc.gov.ph

Beller, L. (2008). International sport management. Champaign, IL: Human Kinetics.

Benson, P. G., Kemery, E. R., Sauser, W. I., \& Tankesley, K. E. (1985). Need for clarity as a moderator of the role ambiguity-job satisfaction relationship. Journal of Management, 11(3), 125-130. https://doi.org/10.1177/014920638501100311

Blanchard, K. (2009). Compatibility in coach-athlete relationships. Sport Psychology, 7, 137-149.

Bob, C. (2012). Social support: An interactional view. Wiley.

Bollen, K. (2003). Expert performance in sport: current perspectives and critical issues. In J. Starkes \& K. A. Ericsson (Eds.), Expert performance in sport: advances in research on sport expertise (pp. 19-48). Human Kinetics.

Carron, A.V. (2002). Sport psychology in the profession of psychology. Professional Psychology, 26(3) 288291.

Case, R. (2006). Team structure and success as related to cohesiveness and leadership. McGraw Hill.

Cassidy, T., Jones, R., \& Potrac, P. (2012). Understanding sports coaching. The social, cultural and pedagogical foundations of coaching practice (2nd ed.). Routledge.

Chelladurai, P., \& Saleh, S. D. (1980). Dimensions of leader behavior in sports: Development of a leadership scale. Journal of Sport Psychology, 2(1), 34-45.

Chemors, G. A. (2012). Characteristics, strategies and knowledge of expert team sport coaches. University of Ottawa, Ontario.

Cho, S., Lee, H.W., \& Magnusen, M. J. (2010) Strength coach-athlete compatibility: Roles of coaching behaviors and athlete gender. International Journal of Applied Sport Sciences, 25(1),55-67.

Christensen, L. (2011). Sports development and fitness options. Heinemann Educational Publishers.

Côté, J., Yardley, J., Hay, J., Sedgwick, W., \& Baker, J. (1999). An exploratory examination of the coaching behavior scale for sport. Avante.

Dieffenbachia, K. (2009). Coaching for the inner edge. Fitness Information Technology. 
Dundee, A. (2011). The interdependence of coaches' and athletes' perceptions and satisfaction with performance. International Journal of Sports Science \& Coaching, 5(2), 69-80.

Gearity, B. T., \& Murray, M. A. (2011). Athletes' experiences of the psychological effects of poor coaching. Psychology of Sport and Exercise, 12(3), 213-221. https://doi.org/10.1016/j.psychsport.2010.11.004

Goleman, L. (2012). Preferred leadership in sports. Applied Sport Sciences, 3, 85-92.

Gutierrez, N. (2012). The problem with the Philippine Sports. Retrieved http://www.Rappler.com/sports/10591-the-problem-with-philippine-sports

Horn, T. S. (2010). Advances in Sport Psychology (2nd ed.). Champaign, Il: Human Kinetics.

Hulin, J. (2010). Coaching preferences of high school girl volleyball players. Perceptual and Motor Skills. 77, 1309-1310.

Jowett, S. (2012). Empathic accuracy in coach-athlete dyads who participate in team and individual sports. Psychology Sport Exercise, 10, 152-158.

Kilburg, R. (2008). Leadership and performance: Beyond expectations. Free Press.

Kowalzyk, N. (2015). The research design in organization studies: Problems and prospects. Organization Science, 6(1), 93-103.

Lei, C. (2011). Individual behavior and group achievement. Oxford University Press.

Lorimer, R. (2011). Beyond winning and losing: Guidelines for evaluating high performance coaches. Sport Psychology, 20, 213-220.

Lumer, C. (2009). The coach-athlete relationship: a motivational mode (4th ed.). Human Kinetics.

Maday, K. M. (2010). Science, knowledge, and sport psychology. The Sport Psychologist, 1, 29-55.

Madrigal, L., \& Porter, L. (2013). A way of being. Houghton Mifflin Company.

Maehr, M. (2009). Culture and achievement motivations. McGraw Hill.

Mageau, G. (2012). Dimensions of coaching behavior, need satisfaction, and the psychological and physical welfare of young athletes. Motivation and Emotion, 28(3), 297-313.

Mallett, C. (2005). Beyond winning and losing: Guidelines for evaluating high performance coaches. Sport Psychology, 20, 213-220.

Marshall, C. (2012). Successful coaching. Human Kinetics.

Mcguire, T. J. (2013). Sport psychology. Prentice Hall.

Poczwardowski, A., Barott, J. E., \& Henschen, K. P. (2002). The athlete and coach: Their relationship and its meaning. Results of an interpretive study. International Journal of Sport Psychology, 33(1), 116-140.

Pyke, F. (2011). Coach effectiveness. Sport Science Review, 2(2) 14-29.

Riemer, H. A., \& Chelladurai, P. (1998). Development of the athlete satisfaction questionnaire (ASQ). Journal of Sport Exercise Psychology, 20, 127 -156.

Robinson, P. (2010). Foundations of sports coaching. Routledge.

Rosandich, P. (2011). The coach. Human Kinetics.

Saleh S. D. (2012). Preferred leadership in sports. Canadian Journal of Applied Sport Sciences, 3, 85-92.

Scott, R. (2011). A coach's responsibility: Learning how to prepare athletes for peak performance. http://thesportjournal.org/article/a-coachs-responsibility

Sherman, C. A. (2011). Achievement goals, motivational climate, and motivational processes. In G. C. Robert (Ed.), Motivation in sports and exercise. Champaign, IL: Human Kinetics.

Smith, R. E., \& Kendall, N. P. (2012). Reduction of children's sport performance anxiety through social support and stress- reduction training for coaches.

Smith, R. E., \& Smoll, F. L. (1997). Coaching the coaches: Youth sports as a scientific and applied behavioral setting. Current Directions in Psychological Science, 6(1), 16-21. https://doi.org/10.1111/1467-8721.ep11512606

Smith, R. E., Smoll, F. L., \& Curtis, B. (1979). Coach effectiveness training: A cognitive-behavioral approach to enhancing relationship skills in youth sport coaches. Journal of Sport Psychology, 1(1), 59-75.

Sriboon, N. (2011). Coach leadership behaviors, team cohesion, and styles in coaching. Athletic Administrator, $13,6-9$.

Stoll, P. (2010). Coaching strategies for youth sports. Joperd, 72, 29-33. 
Terry, P. C. (2001). The coaching preferences of elite athletes competing at universidad. New York: Free Press.

Tiffan, L. (2012). Leader as coach: strategies for coaching and developing others. Personnel Decisions International, 11, 13-25.

Tinning, B. (2004). Satisfaction and commitment of Canadian university athletes: The effect of gender, Journal articles Avante, 4-8.

Weinberg, R. S. (2011). Foundations of sport and exercise psychology (3rd ed.). Human Kinetics.

Weiss, M. R., \& Friedrichs, W. D. (1986). The influence of leader behaviors, coach attributes, and institutional variables on performance and satisfaction of collegiate basketball teams. Journal of Sport Psychology, $8(4), 332-346$.

Wiersma, L. (2008). Athletes' preferences for informational and emotional pre-game speech content. Int J Sports Sci Coach, 2, 171-180.

Williams, J. M. (2009). Causal relationships among cohesion, satisfaction, and performance relationship. Journal of Sport Psychology, 4, 324-337

Zhang, J. (2005). Modification and revision of the leadership scale for sport. Journal of sport behavior, 20(1), $105-122$ 
Belleza, S.

84 Consortia Academia Publishing (A partner of Network of Professional Researchers and Educators) 